\title{
Comparison Between Effect of Glimepiride and Pioglitazone on the C-Reactive Protein Level of Type 2 Diabetic Patient
} AKM FAZULL HAQUE, ${ }^{1}$ MD. ZAHI RUL HAQUE, ${ }^{2}$ ARMSAIFUDDI NEKRAM, ${ }^{3}$ MAZZUL HOQUE, ${ }^{4}$ QUAZ TARI KULISLAM ${ }^{5}$

\begin{abstract}
:
Background: This study was carried out to see the effect of glimepiride and pioglitazone on the serum hs-CRP level in type 2 diabetic patients.

Material and Methods: A non-blind comparative study was conducted among 70 patients with type 2 diabetes (as per WHO criteria) divided into two groups (35 each) to see the effect of glimepiride and pioglitazone on their blood hs-CRP level.

Results: 35 type-2 diabetic patients were given glimepiride. Another 35 patients were given pioglitazone. Fasting blood sugar, $\mathrm{HbAl} \%$, hs-CRP and lipid profile were estimated before and 12 weeks after intervention. The mean change of serum hs-CRP was $1.13 \mathrm{mg} / \mathrm{L}$ to $0.76 \mathrm{mg} / \mathrm{L}$ in pioglitazone group. In glimepiride group the mean change of serum hs-CRP was $0.96 \mathrm{mg} / \mathrm{L}$ to $0.94 \mathrm{mg} / \mathrm{L}$ after 12 weeks. The change was greater in pioglitazone group in comparison to glimepiride group.
\end{abstract}

Conclusion: Reduction of hs-CRP was significant in the study subjects revealing its future potential in reducing the vascular complications of type -2 diabetes mellitus.

Keyword: Type-2 diabetes, hs- CRP, Glimepiride, Pioglitazone, Cardiovascular complication

\section{Introduction}

Diabetes mellitus is a growing health problem that causes significant morbidity and mortality. ${ }^{1}$ It is estimated that more than 3 million people are now suffering from type-2 diabetes in Bangladesh. ${ }^{2}$ Certain proteins known collectively as the "acute phase response" are produced in inflammation mainly by liver. The best known of these are C-reactive protein, a beta-globulin. It is established that, in diabetes hs CRP levels are elevated. ${ }^{3}$ A recent study also proved the same in type2 diabetic patients in Bangladeshi population. ${ }^{4} \mathrm{CRP}$ is directly associated in atherosclerotic plaque formation and increases cardiovascular risks. ${ }^{5}$

Thiazolidinediones improve insulin sensitivity and provide durable glycemic control. They also reduce inflammatory markers, improve vascular function and lipid profiles in patients with type-2 diabetes, which may improve the long term cardiovascular outcomes. ${ }^{6}$ Now a good number of prospective studies are going on in the western world on these relevant field. This is the first study of this kind that has been carried out in Bangladesh. This study was done to see the baseline CRP level in type 2 diabetes patients and effect of thiazolidinediones (pioglitazone) on it.

\section{Materials and Methods}

It was a non-blind comparative study extending from January 2007 to December 2007 done in the Rajshahi Medical College Hospital and in the Rajshahi Diabetic Association Hospital. By purposive sampling method, 70 type-2 diabetic patients were included in this study. Among these 70 patients, 35 were treated with pioglitazone for 12 weeks of time and rest 35 type-2 diabetic patients were treated with glimepiride for the same time. Inclusion criteria were: age $>40 \mathrm{yrs}$, patients with type 2 diabetes (as per WHO criteria) of $<2$ years duration. Exclusion criteria were: patients with $>2$ yrs duration with type 2 , on insulin therapy, patients with $<40$ yrs of age and $>60$ years, smoker, alcoholic, hypertensive, congestive cardiac failure, oedema due to any cause, kidney and liver disease, pregnancy and obesity (BMI $\left.>30 \mathrm{~kg} / \mathrm{m}^{2}\right)$. Data was collected after taking informed consent of the patient. Blood samples were taken for fasting blood glucose (8 hour fasting), 2 hours after breakfast blood sugar, HbA1c (glycosylated haemoglobin), fasting lipid profile, hs-CRP (high sensitive C-reactive protein) at base line and after 3 month intervention. The data was analyzed with the help of SPSS software program. A p-value of $<0.05$ was considered as significant.

1. Medical Officer, Asthma Centre, NIDCH, Mohakhali, Dhaka

2. Assistant Professor of Medicine, Rajshahi Medical College

3. Professor of Medicine, Rajshahi Medical College

4. Associate Professor of Medicine, Rajshahi Medical College

5. Professor of Medicine, Dhaka Medical College

Correspondence: Dr. AKM Fazlul Haque, Medical Officer, Asthma Centre, NIDCH, Mohakhali, Dhaka, E mail: akmhaque60@yahoo.com 


\section{Results}

The results of the study are given in Table I-IV

Table-I

Glycemic status of the study population before and after drug intervention:

\begin{tabular}{|c|c|c|c|c|c|c|c|c|}
\hline \multirow[t]{3}{*}{ Biochemical variables } & \multicolumn{7}{|c|}{ Respondent's group } & \\
\hline & \multicolumn{3}{|c|}{ Pioglitazone } & \multicolumn{5}{|c|}{ Glimepiride } \\
\hline & Male & Female & Total & P-value & Male & Female & Total & P-value \\
\hline FBS before drug (mmol/L) & 10.15 & 9.14 & $9.86 \pm 3.11$ & $<.05$ & 6.86 & 8.04 & $7.72 \pm 1.95$ & .052 \\
\hline FBS after drug(mmol/L) & 8.50 & 7.67 & $8.26 \pm 2.71$ & & 7.16 & 8.46 & $7.37 \pm 3.02$ & \\
\hline 2ABFG before drug(mmol/L) & 15.93 & 13.18 & $15.14 \pm 4.99$ & $<.05$ & 9.57 & 11.07 & $10.21 \pm 4.34$ & .062 \\
\hline 2ABFG after drug(mmol/L) & 11.69 & 11.23 & $11.56 \pm 4.88$ & & 9.32 & 10.24 & $9.71 \pm 5.14$ & \\
\hline $\mathrm{HbA}_{1} \mathrm{c} \%$ before drug & 9.02 & 8.21 & $8.79 \pm 1.45$ & $<.05$ & 7.23 & 7.38 & $7.29 \pm 0.83$ & .067 \\
\hline $\mathrm{HbA}_{1} \mathrm{c} \%$ after drug & 8.11 & 7.52 & $7.94 \pm 1.46$ & & 6.82 & 7.31 & $7.03 \pm 1.12$ & \\
\hline
\end{tabular}

Table II

hsC-RP protein distribution in the study population (before and after drug intervention):

\begin{tabular}{|c|c|c|c|c|c|c|}
\hline & \multicolumn{6}{|c|}{ Respondent's group } \\
\hline & \multicolumn{3}{|c|}{ Pioglitazone } & \multicolumn{3}{|c|}{ Glimepiride } \\
\hline & hs-CRP before drug & hs-CRP after drug & P-value & hs-CRP before drug & hs-CRP after drug & P-value \\
\hline Male & 1.27 & 0.76 & & 1.12 & 0.95 & \\
\hline Female & 0.78 & 0.76 & & 0.74 & 0.93 & \\
\hline Total & $1.13 \pm 1.58$ & $0.76 \pm 1.25$ & $<0.05$ & $0.96 \pm 1.59$ & $0.94 \pm 1.50$ & $>0.05$ \\
\hline
\end{tabular}

Table-III

Lipidemic status of the study population (before and after drug intervention):

\begin{tabular}{|c|c|c|c|c|c|c|c|c|}
\hline & \multicolumn{7}{|c|}{ Respondent's group } & \\
\hline & \multicolumn{4}{|c|}{ Pioglitazone } & \multicolumn{4}{|c|}{ Glimepiride } \\
\hline & Male & Female & Total & P-value & Male & Female & Total & P-value \\
\hline HDL before drug & 39 & 41 & $40 \pm 4$ & $>.05$ & 39 & 39 & $39 \pm 4$ & $>.05$ \\
\hline HDL after drug & 40 & 40 & $40 \pm 4$ & & 40 & 38 & $39 \pm 4$ & \\
\hline LDL before drug & 108 & 131 & $115 \pm 32$ & $>.05$ & 103 & 120 & $110 \pm 25$ & $>.05$ \\
\hline LDL after drug & 110 & 117 & $112 \pm 26$ & & 110 & 126 & $117 \pm 25$ & \\
\hline TC before drug & 200 & 240 & $211 \pm 38$ & $>.05$ & 184 & 220 & $200 \pm 40$ & $>.05$ \\
\hline TC after drug & 199 & 230 & $208 \pm 40$ & & 190 & 222 & $204 \pm 34$ & \\
\hline TG before drug & 211 & 208 & $210 \pm 50$ & $>.05$ & 214 & 226 & $219 \pm 70$ & $>.05$ \\
\hline TG after drug & 210 & 217 & $212 \pm 39$ & & 205 & 231 & $216 \pm 60$ & \\
\hline
\end{tabular}

Table-IV

Changes in mean body weight of the study population (before and after drug intervention):

\begin{tabular}{|c|c|c|c|c|}
\hline Respondent's group & Respondent's gender & Weight before drug & Weight after drug & P-value \\
\hline Pioglitazone & Male & $60.68 \pm 9.886$ & $61.68 \pm 9.835$ & $>0.05$ \\
\hline group & Female & $55.60 \pm 6.995$ & $56.50 \pm 7.352$ & \\
\hline $\mathrm{n}=35$ & Total & $59.23 \pm 9.347$ & $60.20 \pm 9.393$ & \\
\hline Glimepiride & Male & $59.25 \pm 11.580$ & $59.25 \pm 11.111$ & $>0.05$ \\
\hline group & Female & $51.73 \pm 6.798$ & $51.73 \pm 6.734$ & \\
\hline$n=35$ & Total & $56.03 \pm 10.402$ & $56.03 \pm 10.095$ & \\
\hline
\end{tabular}




\section{Discussion}

In our study, we observed the effects of glimepiride and pioglitazone on the hs-CRP level, glycemic and lipidemic status of the type 2 diabetic patient. For this purpose, we enrolled 70 type 2 diabetic patients. Among them 35 were treated with pioglitazone $30 \mathrm{mg}$ in the morning for 12 weeks of time and rest 35 type- 2 diabetic patients were treated with glimepiride (1 to $6 \mathrm{mg}$, according to the glycemic status) for the same time.

In this study the control of glycemic status was suboptimal in both group with the drug intervention, i.e. mean $\mathrm{HbA} 1 \mathrm{c} \%$ was reduced $8.79 \%$ to $7.94 \%$ in pioglitazone group and $7.29 \%$ to $7.03 \%$ in glimepiride group. Reduction of mean fasting blood sugar in pioglitazone group was $9.86 \mathrm{mmol} / \mathrm{L}$ to $8.26 \mathrm{mmol} / \mathrm{L}$, whereas in glimepiride group it was reduced $7.72 \mathrm{mmol} / \mathrm{L}$ to $7.37 \mathrm{mmol} / \mathrm{L}$. Though the reduction of both $\mathrm{HbA} 1 \mathrm{c} \%$ and fasting blood sugar was suboptimal, but the reduction in pioglitazone group was significant $(\mathrm{p}<.05)$ and in glimepiride group was near to significant $(\mathrm{P}=0.067$ and $\mathrm{P}=0.052$ respectively) (Table-I). The mean change of HbA1c\% was $0.85 \%$ in pioglitazone group and $0.26 \%$ in glimepiride group. The change in pioglitazone group was significant $(\mathrm{P}<0.05)$.

In this study there was change of serum mean hs-CRP level from $1.13 \mathrm{mg} / \mathrm{L}$ to $0.76 \mathrm{mg} / \mathrm{L}$ in pioglitazone group after 12 weeks of pioglitazone (30 gm) intervention and in glimepiride group who did not receive pioglitazone, the change of serum mean hs-CRP level was $0.96 \mathrm{mg} / \mathrm{L}$ to $0.94 \mathrm{mg} / \mathrm{L}$ after 12 weeks (Table-II). This change in hs-CRP in pioglitazone group in comparison to glimepiride group is statistically significant (p>0.05).

Haffiner SM et al. in 2002 showed that the decline in CRP was $0.155 \mathrm{mg} / \mathrm{dl}$ in placebo group, $0.52 \mathrm{mg} / \mathrm{dl}$ in rosiglitazone $8 \mathrm{mg} /$ day group. ${ }^{7}$ The decline in CRP in placebo group was not significant but in rosiglitazone group was significant $(\mathrm{P}<0.05)$. Pfutzner A et al. showed in 2005 that a significant reduction of hs-CRP was seen after six months of therapy in pioglitoazone (-0.10 $\pm 2.25 \mathrm{mg} / \mathrm{dl},-29 \%$, endpoint vs, baseline, $\mathrm{p}<0.01$ ) while no such change could be seen during glimepiride treatment $\left(0.2 \pm 4.0 \mathrm{mg} / \mathrm{dl},-4 \%\right.$, $\mathrm{p}=$ not significant) ${ }^{8}$ Mohanty and his colleagues reported a decrease in CRP of $30 \%$ when 11 obese patients without diabetes were treated with rosiglitazone $4 \mathrm{mg}$ daily for 6 weeks. ${ }^{9}$

These studies are consistent with our studies regarding the reduction of serum hs-CRP level of type 2 diabetic patients by the use of thiazolidinediones. So we can conclude that thiazolidinediones can be used for type 2 diabetic patients to reduce the diabetes and its related cardiovascular complications.
In our study there was no change in high density lipoprotein (HDL) cholesterol (39 $\mathrm{mg} / \mathrm{dl}$ ) before and after drug in glimepiride group and $40 \mathrm{mg} / \mathrm{dl}$ before and after drug in pioglitazone group. Total cholesterol raises mildly in glimepiride group (200 mg/dl to $209 \mathrm{mg} / \mathrm{dl}$ ) after treatment with glimepiride but mildly decreased in pioglitazone group after treatment with pioglitazone ( $211 \mathrm{mg} / \mathrm{dl}$ to $208 \mathrm{mg} / \mathrm{dl})$. Similar mild elevation in low density lipoprotein LDL cholesterol in glimepiride group ( $110 \mathrm{mg} / \mathrm{dl}$ to $117 \mathrm{mg} / \mathrm{dl})$ and mild decrease in pioglitazone group after pioglitazone intervention (115 mg/dl to $112 \mathrm{mg} / \mathrm{dl}$ ). Triglyceride level was rather slightly raised in pioglitazone group after pioglitazone intervention ( $210 \mathrm{mg} / \mathrm{dl}$ to $212 \mathrm{mg} / \mathrm{dl}$ ) and mildly reduced in glimepiride group ( $219 \mathrm{mg} / \mathrm{dl}$ to $216 \mathrm{mg} / \mathrm{dl}$ ) (Table-III). In a word there was no significant change in lipid profile after drug intervention in our study ( $\mathrm{p}>0.05)$.

Ghazzi and his collagues demonstrated that the troglitazone therapy decreased triglyceride level while increased high density lipoprotein (HDL) level in patients with type 2 diabetes. ${ }^{10}$ Similarly , treatment with 15,30 and $45 \mathrm{mg}$ of pioglitazone significantly decreased triglyceride compared with placebo $(\mathrm{P}<0.05)$ and significantly increased HDL cholesterol $(\mathrm{P}<0.05) .{ }^{11}$ Rosiglitazone therapy also decreased triglyceride in patients with a high baseline level increased HDL cholesterol by $10 \%$ to $30 \% .{ }^{12}$

Ours results regarding effect of pioglitazone on the lipids is not fully consistent with the above studies. This may be due to the short durations of drug application (12 weeks only) as well as use of low dose of pioglitazone (30mg), or may be due to dietary habit of our diabetic patients, because carbohydrates (rice and bread) are the main foods of our patients.

In our study population none developed pedal oedema, pulmonary oedema and congestive heart failure or became anaemic, but there was little weight gain in pioglitazone group who received pioglitazone ( $30 \mathrm{mg}$ ) for 12 weeks. There was no change in weight in glimepiride group after 12 weeks of treatment with glimepiride (Table-IV). In pioglitazone group mean increase in weight in male was $1 \mathrm{~kg}$ and in female it was $0.9 \mathrm{~kg}$ only and this increase in weight was not significant $(\mathrm{P}>0.05)$ in comparison to glimepiride group. Haffiner SM et al. showed that after 26 weeks of rosiglitazone treatment, patients in the placebo group lost $1.1 \mathrm{~kg}$ as opposed to 1.8 $\mathrm{kg}$ increase in the rosiglitazone $4 \mathrm{mg} /$ day group and $3.5 \mathrm{~kg}$ increase in rosiglitazone $8 \mathrm{mg} /$ day group $(\mathrm{P}<0.001$ compared with baseline). Our study is consistent with these studies. ${ }^{7}$

\section{Conclusion}

This small study may not reflect the exact situation of the fact in the community but its proximity to the reality can not 
be underestimated. The reduction of hs-CRP level in pioglitazone group was significant in comparison to glimepiride group ( $0.39 \mathrm{mg} / \mathrm{L} \mathrm{Vs} 0.02 \mathrm{mg} / \mathrm{L}$ ). Other effects of pioglitazone, like hypoglycemic effect and effect on lipid profile were also satisfactory and no significant adverse effect was demonstrated. As diabetes is a growing epidemic globally, the morbidity and mortality of diabetes is also gradually increasing. This morbidity and mortality is mainly due to vascular complications of type-2 diabetes (stroke, myocardial infarction). It is now proved that these vascular complications, especially macrovascular complications are due to induction of chronic inflammations resulting from insulin resistance which leads to atherosclerosis. So, to prevent these incidence thiazolidinediones (pioglitazone) may be used as early pharmacological therapy in type- 2 diabetic patients.

\section{Conflict of Interest: None}

\section{References:}

1. American Diabetes Association. Standards of medical care in diabetes. Diabetes Care 2004; 27 (suppl 1): S15-S35

2. Bari AHMR. Bangladesh: many barriers to optimal treatment, In: Rab OA, Alam AK (eds). Diabetes News Letter 2006; 4(1): 1-5

3. Gale EAM, Anderson JV. Diabetes mellitus and other disorders of metabolism. In: Kumar P, Clark M (eds). Clinical Medicine. $6^{\text {th }}$ ed. London: Elsevier 2005; pp 200, 421, 11011133

4. A.K.M. Fazlul Haque, A.R.M. Saifuddin Ekram, Quazi Tarikul Islam, et al. Evaluation of Serum High Sensitivity C -Reactive Protein (hs-CRP) In Type-2 Diabetic Patient. J Medicine 2010; 11: 20-23

5. Paul A, Kerri WS, et al. C-reactive protein accelerates the progression of atherosclerosis in apolipoprotein E-deficient mice. Circulation 2004; 109: 647-655
6. Ismail F. Current Management of type 2 diabetes: Why Thiazolidinediones Should be the Cornerstone of Therapy. The Journal of Applied research 2004; 4 (3): 439

7. Haffiner SM. Greenberg AS, Weston WM, Chen H, William K, Freed M I. Effect of Rosiglitozone Treatment on Nontraditional Markers of cardiovascular Disease in patients With Type 2 Diabetes Mellitus. Circulation 2002; 106: 679

8. Pfutzner A, Marx N, Lubben G, et al. Improvement of cardiovascular Risk Markers by Pioglitozone is Independent From Glycemic control. J Am Coll Cardiol 2005; 45: 19251931

9. Mohanty P, Aljada A, Ghanim H, et al. Rosiglitazone improves vascular reactivity, inhibits reactive oxygen species (ROS) generation, reduces $\mathrm{p} 47^{\text {phox }}$ subunit expression in mononuclear cells (MNC) and reduces $C$ reactive protein (CRP) and monocyte chemotactic protein-1 (MCP-1): evidence of a potent anti-inflammatory effect. Diabetes 2001; 50(suppl 2): A68

10. Ghazzi MN, Perez JE, Antonucci TK, et al. Cardiac and glycemic benefits of troglitazone treatment in NIDDM. The Troglitazone Study Group. Diabetes 1997; 46: 433-439

11. Aronoff S Rosenblatt S, Braithwaite S, Egan JW, Mathisen AL, Schneider RL. Pioglitazone hydrochloride monotherapy improves glycemic control in the treatment of patients with type 2 diabetes: a 6-month randomized placebo-controlled dose-response study. The Pioglitazone 001 Study Group. Diabetes Care 2000; 23: 1605-1611

12. Lebovitz HE, Dole JF, Patwardhan R, Rappaport EB, Freed MI. Rosiglitazone Clinical Trials Study Group. Rosiglitazone monotherapy is effective in patients with type 2 diabetes [erratum appears in J Clin Endocrinol Metab 2001; 86: 1659]. J Clin Endocrinol Metab 2001; 86: 280-288 